\title{
Abnormal eye movements in parkinsonism: a historical view
}

\author{
Movimentos oculares anormais em parkinsonismo: uma visão histórica \\ Tereza KO', Augusto Mädke BRENNER', Nicholas Pili MONTEIRO', Mariana Severo DEBASTIANI', \\ Alberto Chitolina NESELLO', Arlete HILBIG ${ }^{2,3}$
}

\begin{abstract}
Parkinson's disease (PD), known since ancient times as paralysis agitans, was studied and described by James Parkinson in 1817 in his work "An Essay on the Shaking Palsy". Fifty years later, Charcot and his students delved into the disease, naming it as we know it today, as well as defining the classic disease and its variants. One of these students, Arthur Dutil, addressed patients' abnormal eye movements. Nowadays, it is known that the differential diagnosis of PD is relevant for prognosis, treatment and research, and, despite the advances in the area, it remains largely clinical. The relevance of the eye movement exam has grown along with the history of PD and it has proved to be an excellent tool for the differential diagnosis of parkinsonism. Additionally, it can become a support to identify different types of genetic PD and be useful for improving early recognition of cognitive decline in patients with PD.
\end{abstract}

Keywords: Eye Movements; History of Medicine; Parkinson Disease; Parkinsonian Disorders.

\section{RESUMO}

A doença de Parkinson (DP), conhecida desde a antiguidade como paralysis agitans, foi estudada e descrita por James Parkinson em 1817 em seu trabalho An Essay on the Shaking Palsy. Cinquenta anos depois, Charcot e seus alunos aprofundaram os estudos na doença, nomeando-a como a conhecemos atualmente, bem como definindo a doença clássica e suas variantes. Um desses estudantes, Arthur Dutil, investigou os movimentos oculares anormais nos pacientes. Hoje, sabe-se que o diagnóstico diferencial da DP é relevante para o prognóstico, tratamento e pesquisa, e, apesar dos grandes avanços na área, ainda permanece amplamente clínico. A relevância do exame de movimentação ocular cresceu com a história da DP e este se mostrou uma excelente ferramenta para o diagnóstico diferencial do parkinsonismo. Além disso, pode se tornar um auxílio para identificar diferentes formas de DP genética e útil para melhorar o reconhecimento precoce do declínio cognitivo em pacientes com DP.

Palavras-chave: Movimentos Oculares; História da Medicina; Doença de Parkinson; Transtornos Parkinsonianos.

In the year of 1817, James Parkinson (1775-1824), a physician and geologist who lived near London, England, published his monograph "An Essay on the Shaking Palsy"'. Within his work, he described greatly what had been seen a long time before him by individuals like Galen ${ }^{23}$, known at that time as paralysis agitans. Approximately fifty years after his publication, Jean-Martin Charcot (1825-1893) and his students at the Salpêtrière Hospital in Paris, France, complemented the analyses of the disease by naming it as we know today, Parkinson's disease (PD), and distinguishing it from other similar diseases at that time, as multiple sclerosis ${ }^{24}$.
Furthermore, Charcot and his students identified atypical variants of what was defined as the classic PD. Those variants were called PD without tremor, PD with hemiplegia, and PD with extended posture ${ }^{25}$. Nowadays, these variants are known to be atypical parkinsonism, as progressive supranuclear palsy (PSP), multiple system atrophy (MSA) and corticobasal degeneration (CBD) ${ }^{2}$.

Among different predominant features of PD seen at that time, as bradykinesia and rigidity, one of Charcot's students, Arthur Dutil, described, in 1889, a woman with parkinsonian features and abnormal eye movements. Although no clear

\footnotetext{
${ }^{1}$ Universidade Federal de Ciências da Saúde de Porto Alegre, Faculdade de Medicina, Porto Alegre RS, Brazil.

${ }^{2}$ Universidade Federal de Ciências da Saúde de Porto Alegre, Departamento de Clínica Médica, Porto Alegre RS, Brazil.

${ }^{3}$ Irmandade Santa Casa da Misericórdia de Porto Alegre, Serviço de Neurologia, Porto Alegre RS, Brazil.

Tereza KO (D) https://orcid.org/0000-0001-5179-7230; Augusto Mädke BRENNER (iD https://orcid.org/0000-0003-0512-8268;

Nicholas Pili MONTEIRO (iD https://orcid.org/0000-0003-3054-2647; Mariana Severo DEBASTIANI (ID https://orcid.org/0000-0002-0635-514X;

Alberto Chitolina NESELLO (iD) https://orcid.org/0000-0002-4845-279X; Arlete HILBIG (iD) https://orcid.org/0000-0003-1476-2105

Correspondence:Tereza Ko; E-mail:terezak@ufcspa.edu.br

Conflict of interest: There is no conflict of interest to declare.

Authors' contributions: TK: conceptualization, data curation, investigation, methodology, project administration, writing-original draft, writing-review \& editing. AMB, NPM, MSD, ACN: conceptualization, data curation, investigation, methodology, writing-original draft, writing-review \& editing. AH: conceptualization, data curation, investigation, methodology, project administration, supervision, validation, visualization, writing-original draft, writing- review \& editing.

Received on August 24, 2020; Received in its final form on October 06, 2020; Accepted on October 13, 2020.
} 
description of supranuclear palsy was reported, the presence of retrocollis and erect trunk suggest a PSP phenotype ${ }^{6}$. Prior to Dutil, in 1838, an interesting report was made by Marshall Hall, when he wrote "a peculiar lateral rocking motion of the eyes" regarding a 28-year-old male thought to be a case of $\mathrm{PD}^{7}$.

Throughout the first half of the $20^{\text {th }}$ century, authors, including E. Krebs, in 1925, and A. Bielschowsky, in 1935, have described abnormal eye movements in patients with $\mathrm{PD}^{8}$. Fisher, in 1924, and Portman, in 1932, found first degree spontaneous nystagmus that appears when the patient gazes in the direction of the fast component to be frequent in $\mathrm{PD}^{9,10}$. After the influenza epidemic of 1916-1917, there was an important increase in cases of postencephalitic parkinsonism². Therefore, many studies were based on the observation of postencephalitic parkinsonism cases $^{11}$, which occur with characteristic oculogyric crisis, pupillary changes, and gaze palsies ${ }^{12}$. Alexandre, in 1939, and Fracasso and Palatini, in 1941, however, found first degree spontaneous nystagmus to be rare in patients with PD.

Research on abnormal eye movements in parkinsonian disorders was intensified in the second half of the $20^{\text {th }}$ century (Figure 1). In 1972, Corin et al. ${ }^{8}$ published an important case-control study on oculomotor dysfunction in $\mathrm{PD}^{8}$ and described some dysfunctions as the saccadic, pursuit, and vergence in approximately $75 \%$ of patients. As the criteria for $\mathrm{PD}$ was not mentioned in these ancient studies, we can assume that at least part of their sample had parkinsonian syndrome other than PD as we define today.
By the year of 2020, much has been known about the association of parkinsonism and abnormal eye movements, their role in differential diagnosis of parkinsonian disorders, and their potential aid to better elucidate diseases pathophysiology.

Among parkinsonism and movement disorders, PD appears to have less prominent oculomotor abnormality ${ }^{13}$ (Table 1). Nevertheless, hypometric voluntary saccades, saccadic intrusions during eye fixation, impaired vertical soft search/tracking movements and convergence insufficiency can be seen in PD and worsen as disease progresses ${ }^{13,14}$. In comparison, PSP patients present oculomotor disorders in early disease stage, including frequently slow vertical saccades with normal speed horizontal saccades (although often hypometric) that also become slow with disease progression, and impaired convergent ocular movements and linear vestibulo-ocular reflex. PSP is liable to be confused with CBD in consequence of the vertical paralysis of supranuclear gaze ${ }^{13,14}$. However, it was observed that CBD presents with significant increased latency of horizontal saccades, while PSP presents with a decrease of saccade speed ${ }^{13,14}$.

In 2016, Yu et al. ${ }^{15}$ drew attention to reading disturbance in PD analyzing a 40-year-old man with a six-year history of disease. The man was on dopamine-replacement therapy, had high schooling levels and good eye movement control. His ability in making alternating fixations and saccades during number reading was normal on the neuro-ophthalmic examination. Nevertheless, his word reading was significantly slowed and abnormal due to increased number of saccades,

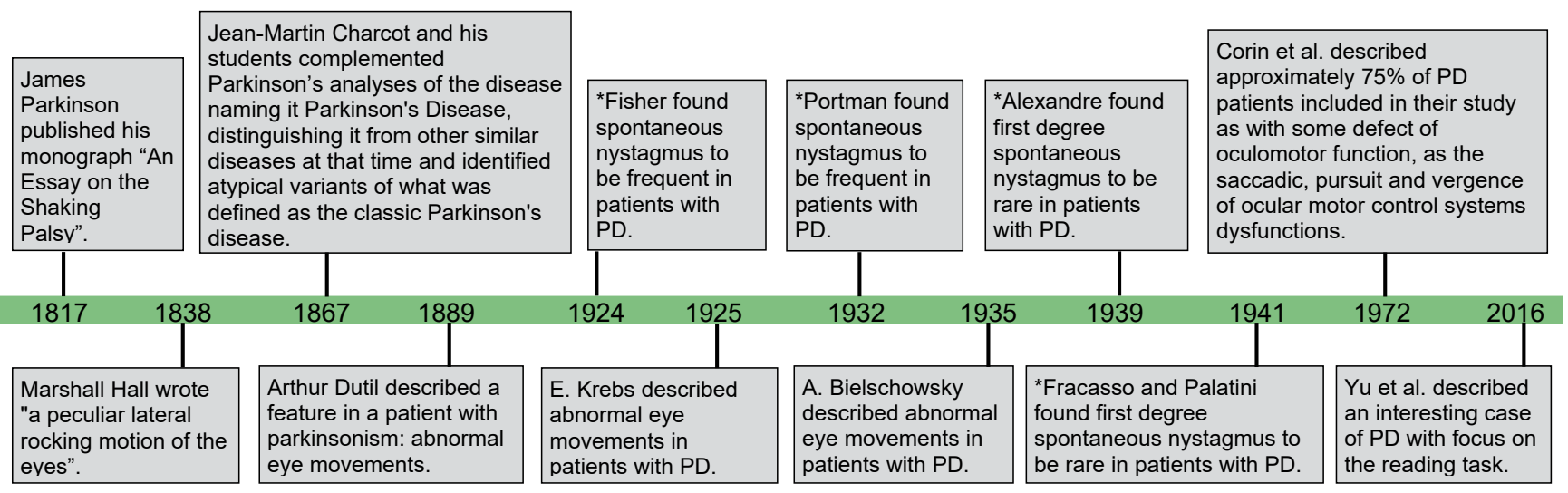

PD: Parkinson's disease.

*Nowadays, physicians understand that nystagmus is not a feature of PD.

Figure 1. Parkinson's disease and Parkinsonisms' timeline.

Table 1. Ocular motor abnormalities in parkinsonism, adapted from Jung ${ }^{13}$.

\begin{tabular}{|c|c|c|c|c|}
\hline Diagnosis & Parkinson's disease & $\begin{array}{l}\text { Progressive supranuclear } \\
\text { palsy syndrome }\end{array}$ & $\begin{array}{l}\text { Corticobasal } \\
\text { syndrome }\end{array}$ & $\begin{array}{l}\text { Multiple systemic } \\
\text { atrophy }\end{array}$ \\
\hline Saccadic intrusions & + & ++ & + & + \\
\hline Vertical saccades & Hypometric & Slowed, early & Impaired, late & Hypometric \\
\hline Horizontal saccades & Hypometric & Slowed, late & Delayed & Hypometric \\
\hline Blepharospasm or eyelid apraxia & Very rare & Common & Common & Rare \\
\hline Smooth pursuit & Mild & Severe & Mild & Moderate \\
\hline
\end{tabular}


smaller saccade amplitudes, increased number of regressive saccades and longer fixation durations.

Waldthaler et al. ${ }^{16}$, in 2018, also characterized eye movements during reading in PD patients. They suggest that eye movements during reading reflect cognitive impairment in PD. Wong et al. ${ }^{17}$ had explored the relationship between the eye movement parameters and performance in cognitive tests in multiple domains. As a result, it was found that the prolonged duration of fixation was associated with poorer performance in verbal fluency, visual and verbal memory. Gorges et al..$^{18}$ analyzed eye movements using video-oculography and correlated the findings with functional brain mapping obtained from task-based/no-task-based functional magnetic resonance imaging (MRI). The results show that the worst oculomotor performance is associated with the severity of the functional impairment of the brain structures involved with the disease. These findings may allow further exploration of the use of eye movement parameters as a clinical proxy for cognitive function markers in patients with PD. Similarly, Barbosa et al. described an association between the saccadic direction error with impulse-compulsive behavior in PD patients ${ }^{19}$.
Another interesting line of study is the analysis of the different inherited parkinsonian syndromes and their dysfunction profiles in the basal ganglia. The study, carried out in 2017 by Pretegiani et al. ${ }^{20}$, compared the pattern of alteration of attributes of horizontal saccades, vertical saccades and antisaccades in PD and different forms of genetic parkinsonism, such as PARK1, PARK2, PARK6 and PARK9 inherited forms of PD, in addition to neurodegeneration with brain iron accumulation (NBI) and Gaucher Disease, among others. The results show that each one of the mentioned diseases may have a different pattern of changes in the saccadic movements. Such a study allows important inferences to be made about the different dysfunctions presented by the basal ganglia in these syndromes.

In conclusion, the differential diagnosis of PD is relevant for prognosis, treatment, and research, and, despite major advances in the field, it still remains largely clinical. The relevance of eye movement examination has grown alongside the history of PD and has proven to be an excellent tool for differential diagnosis of parkinsonism ${ }^{13,21}$. Moreover, it may become an aid to identify different forms of genetic PD, and useful to improve early recognition of cognitive decline in PD patients.

\section{References}

1. Parkinson J. An essay on the shaking palsy. J Neuropsychiatry Clin Neurosci. 2002 Spring;14(2):223-36; discussion 222. https://doi. org/10.1176/jnp.14.2.223

2. Goetz CG. The history of PD: Early clinical descriptions and neurological therapies. Cold Spring Harb Perspect Med. 2011 Sep;1(1):1-15. https://doi.org/0.1101/cshperspect.a008862

3. Duvoisin RC. A Brief History of Parkinsonism. Neurol Clin. 1992 May;10(2):301-16. https://doi.org/10.1016/S0733$8619(18) 30211-1$

4. Goetz CG. Charcot on Parkinson's disease. Mov Dis. 1986;1(1):27-32 https://doi.org/10.1002/mds.870010104

5. Obeso JA, Stamelou M, Goetz CG, Poewe W, Lang AE, Weintraubet D, et al. Past, present, and future of PD: A special essay on the 200th Anniversary of the Shaking Palsy. Mov Dis. 2017 Sep;32(9):1264-310. https://doi.org/10.1002/mds.27115

6. Goetz CG. An Early Photographic Case of Probable Progressive Supranuclear Palsy. Mov Dis. 1996 Nov;11(6):617-8. https://doi. org/10.1002/mds.870110604

7. Goldman J, Goetz CG. History of PD. In: Koller W, Melamed E. Handbook of Clinical Neurology. 3rd series. Amsterdam: Elsevier BV; 2007. p. 107-28.

8. Corin MS, Elizan TS, Bender M.B. Oculomotor Function in Patients with PD. J Neurol Sci. 1972 Mar;15(3):251-65. https://doi. org/10.1016/0022-510x(72)90068-8

9. Mingino S, Veronese A. Modifications of the vestibulo-ocular responses in parkinsonian patients after thalamolysis. An electronystagmographic study. Confin Neurol. 1965;26(3):451-5. https://doi.org/10.1159/000104065

10. Chapter III: Nystagmus. Acta Oto-Laryngologica. 1976;81:sup343:2335. https://doi.org/10.3109/00016487609135092

11. Shibasaki H, Tsuji S, Kuroiwa Y. Oculomotor abnormalities in PD. Arch Neurol. 1979 Jun; 36(6):360-4. https://doi.org/10.1001/ archneur.1979.00500420070009
12. Rail D, Scholtz C, Swash M. Post-encephalitic parkinsonism: current experience. J Neurol Neurosurg Psychiatry. 1981 Aug;44(8):670-6. https://doi.org/10.1136/jnnp.44.8.670

13. Jung I, Kim J. Abnormal eye movements in Parkinsonism and movement disorders. J Mov Disord. 2019 Jan;12(1):1-13. https://doi. org/10.14802/jmd.18034

14. Crotty GF, Chwalisz, BK. Ocular motor manifestations of movement disorders. Curr Opin Ophthalmol. 2019 Nov;30(6):443-8. https://doi. org/10.1097/ICU.0000000000000605

15. Yu C, Lee T, Shariati M, Santini V, Poston K, Liao YJ. Abnormal eye movement behavior during reading in PD. Parkinsonism Relat Disord. 2016 Nov;32:130-2. https://doi.org/10.1016/j.parkreldis.2016.08.008

16. Waldthaler J, Tsitsi P, Seimyr GÖ, Benfatto NM, Svenningsson P. Eye movements during reading in PD: a pilot study. Mov Dis. 2018 Oct;3(9):1661-2. https://doi.org/10.1002/mds.105

17. Wong OWH, Fung GPC, Chan S. Characterizing the relationship between eye movement parameters and cognitive functions in nondemented Parkinson's disease patients with eye tracking. J Vis Exp. 2019 Sep;151:1-11. https://doi.org/10.3791/60052

18. Gorges M, Müller H, Kassubek, J. Structural and functional brain mapping correlates of impaired eye movement control in parkinsonian syndromes: a systems-based concept. Front Neurol. 2018 May;9:319. https://doi.org/10.3389/fneur.2018.00319

19. Barbosa P, Kaski D, Castro P, Lees AJ, Warner TT, Djamshidian A. Saccadic direction errors are associated with impulsive compulsive behaviours in Parkinson's disease patients. J Parkinsons Dis. 2019;9(3):625-30. https://doi.org/10.3233/JPD-181460

20. Pretegiani E, Optican LM. Eye movements in Parkinson's Disease and inherited parkinsonian syndromes. Front Neurol. 2017 Nov;8:592. https://doi.org/10.3389/fneur.2017.00592

21. Terao Y, Tokushigeet S, Inomata-Terada S, Fukuda H, Yugeta A, Ugawa Y. Differentiating early PD and multiple systems atrophy with parkinsonism by saccade velocity profiles. Clin Neurophysiol. 2019 Dec;130(12):2203-15. https://doi.org/10.1016/j.clinph.2019.09.004 